\title{
Nontoxic glasses: Preparation, structural, electrical and biological properties
}

\author{
Sílvia R. Gavinho' (D) | Pedro R. Prezas ${ }^{1} \quad$ Diogo J. Ramos $^{2} \quad$ Isabel Sá-Nogueira ${ }^{3}$ | \\ Joao P. Borges ${ }^{2}$ | M. Carmo Lança ${ }^{2}$ | Jorge C.Silva ${ }^{2}$ | Célia M. R. Henriques ${ }^{2}$ | \\ Eduardo Pires $^{4}$ ｜ Jakka Suresh Kumar ${ }^{1}$ ｜ M. P. F. Graça ${ }^{1}$
}

${ }^{1}$ I3N and Physics Department, Aveiro

University, Aveiro, Portugal

${ }^{2}$ I3N-CENIMAT, New University of

Lisbon, Lisbon, Portugal

${ }^{3}$ UCIBIO, REQUIMTE, Departamento

Ciências da Vida, Faculdade de Ciências e

Tecnologia, FCT-UNL, Lisbon, Portugal

${ }^{4}$ Ceramed-Medical Coatings S.A., Lisbon,

Portugal

\section{Correspondence}

S. R. Gavinho, I3N and Physics

Department, Aveiro University, Aveiro,

Portugal.

Email: silviagavinho@ua.pt

\section{Funding information}

FEDER funds through the COMPETE 2020

Program; National Funds through FCT-

Portuguese Foundation for Science and

Technology

\begin{abstract}
Bacterial infections affect about 1 in 5 patients who receive a dental implant within 5 years of surgery. To avoid the implant rejection it is necessary for the development of innovative biomaterials, with addition or substitution of the ions, for implant coatings that promote a strong bond with the new host bone and antibacterial action. The objective of this work was to synthesize a bioactive glass with different silver concentrations to evaluate their antibacterial performance. The glasses were synthesized with up to $2 \%$ silver content by melt-quenching. Structural, morphological, biological, and electrical properties of all samples were studied. The biological behavior was evaluated through cytotoxicity tests and antibacterial activity. The structural analysis shows that the introduction of silver do not promote significant changes, not altering the advantageous properties of the bioglass of the bioglass. It was verified that the glasses with a silver content from $0.5 \%$ to $2 \%$, completely prevented the growth of both Staphylococcus aureus and Escherichia coli while being nontoxic toward mammalian cells. Therefore, these bioglasses are promising materials to be used in the production of dental implants with antimicrobial activity.
\end{abstract}

\section{K E Y W O R D S}

antibacterial properties, bioactive glass, biomaterial, cytotoxicity, electrical properties

\section{1 | INTRODUCTION}

Oral titanium implants have become a widely used option in replacing lost teeth. Most clinical studies have shown very positive and promising results for the use of dental implants, using implant survival as an indicator. ${ }^{1}$ However, this practice is not yet fully devoid of drawbacks, as in some cases there are complications after implantation. Excessive occlusal stress, host characteristics and bacterial induced bone loss (peri-implantitis) are some of the etiological factors for late loss of implanted bone structure. ${ }^{2}$ Peri-implantitis arises from inflammatory reactions associated with loss of the supporting bone around an implant. This bacterial infection is the main cause of implant loss. To avoid nonconservative treatments (removal of the implant), because this alternative is a very complex and traumatic procedure for both the patient and the professional, new approaches to implant structure and/or composition are required. It has been reported the use of bioactive glasses can prevent removal of the implant. ${ }^{3}$ This type of material has shown great relevance due to its ease in increasing tissue integration and accelerating the regeneration of soft and hard tissues. ${ }^{4-7}$ Biomaterials are classified as biocompatible materials that are introduced into the biological environment and are assimilated by the tissues of the human body. They may present as bioinert 
(no reaction), resorbable (reactivity and disappearance of material) or bioactive (create a binding with living tissue) ${ }^{8,9}$ When implanted in the form of porous structures, they promote tissue ingrowth. Bioactivity is one of the main requirements to be taken into account in bone tissue engineering. This characteristic is attributed to the formation of a surface layer of hydroxylated apatite (HCA) similar to bone mineral. ${ }^{10}$ Bioactive glasses, when compared to other ceramics, increase bone regeneration, acting on cells at the genetic level. ${ }^{6}$ After contact of bioactive glasses with the biological medium, ion release occurs that promotes the growth of a layer of carbonated hydroxyapatite on the surface of the glass. The presence of network modifiers, such as sodium and calcium, in the $\mathrm{SiO}_{2}$ network intensifies the level of this dissolution, leading to the formation of bridged silicon-oxygen bonds. Whenever there are phosphate ions in the bioactive glass network, these are also released, further promoting $\mathrm{Si}-\mathrm{OH}$ bonds. This increase in $\mathrm{Si}-\mathrm{OH}$ bonds depends on the hydrolysis of the Si-O-Si bonds caused by the increase in $\mathrm{pH}$. Then, the migration of $\mathrm{Ca}^{2+}$ and $\mathrm{PO}_{4}{ }^{3-}$ ions to the surface occurs, promoting the formation of an amorphous layer of calcium phosphate. This layer, through the incorporation of hydroxides and carbonate ions of the biological fluid, crystallizes in hydroxyapatite. As bioactivity is directly related to the rate of dissolution of glass, morphology is an important factor. ${ }^{11,12}$

The first bioactive glass, $45 \mathrm{~S} 5$ Bioglass ${ }^{\circledR}$ was reported by Hench et al in $1969 .{ }^{13}$ It has been used in a number of biomedical applications such as orthopedic implants, bone filler and treating conductive deafness and alveolar ridge resorption. ${ }^{14}$ Bioglass ${ }^{\circledR}$ presents higher bioactivity, having been applied in more than 1 million patients for jaw defects repair and orthopedic-related interventions. ${ }^{6}$ However, bacterial infection has been an obstacle in clinical applications that may hinder further adoption of bioactive materials. Thus, to stimulate regeneration, angiogenesis, and antibacterial properties of bioactive glasses in a physiological environment, it was necessary to investigate alternatives. These consist in the introduction or substitution of several metal ions in the glass net. ${ }^{15}$ Many researchers have suggested bioglasses with different therapeutic agents such as silver $(\mathrm{Ag})$, copper $(\mathrm{Cu})$, zinc $(\mathrm{Zn})$, and magnesium $(\mathrm{Mg}){ }^{16-19}$ Silver ions have been shown to have an enormous potential for antimicrobial activity. ${ }^{20,21}$ In addition, the silver cation does not develop bacterial resistance. Researchers have reported that silver-containing silica glasses have a greater antibacterial effect than nondoped silica glasses and a result silver has been incorporated into the surface of a variety of medical devices. ${ }^{22}$ The main benefit of the insertion of silver ions in the matrix of a bioglass is to promote controlled delivery of the antibacterial agent. In addition, a broad spectrum of pathogens found at implant, including Pseudomonas aeruginosa, Escherichia coli, Staphylococcus aureus and Staphylococcus epidermidis, can be affected. The mechanism of the antimicrobial effects of silver is not yet fully understood. Silver ions have a negative impact on bacterial enzymes, nucleic acids, inhibit cell division, damage the cell envelope and bacterial contents, cause structural abnormalities in the cytoplasmic membrane and outer cell layers. ${ }^{23,24}$ The interaction between silver and the constituents of the bacterial cell envelope and consequent damage to the membranes and impact in the intracellular metabolic activity might be responsible for cell death. Due to the greater effectiveness of silver, this process has been the object of extensive research that revealed that its incorporation does not have a detrimental effect on the bioactivity of glass. ${ }^{25}$ Due to its highly promising antibacterial and anti-inflammatory properties, silver-doped bioactive glasses are considered very useful for tissue engineering applications. ${ }^{26}$

In this work, 45S5 base glasses, modified with the addition of silver up to $2 \%$ in weight, were prepared by melt-quenching and their structure, morphology, electrical, and antibacterial activity measurements were performed. The major topic is to evaluate the antibacterial properties. Electrical properties were added to this work by the multifunctionality of these materials, namely by the potential of being electrically polarized, optimizing the osseointegration reactions.

\section{$2 \mid$ EXPERIMENTAL METHODS}

\section{1 | Glass synthesis}

The formulation of the synthesized bioglasses was based on the 45S5 Bioglass ${ }^{\circledR}$ proposed by Larry L. Hench. ${ }^{13}$ The prepared glass composition was $45 \% \mathrm{SiO}_{2}, 24.5 \% \mathrm{Na}_{2} \mathrm{O}$, $24.5 \% \mathrm{CaO}$, and $6 \% \mathrm{P}_{2} \mathrm{O}_{5}(\mathrm{wt} \%)$. In addition to the base bioglass, bioglass was synthesized with various percentages by weight of $\mathrm{AgNO}_{3}$ (BG0.5, BG1 and BG2\%wt), substituting the amount of $\mathrm{Na}_{2} \mathrm{CO}_{3}$. In a first stage, the high-purity starting chemicals $\left(\mathrm{SiO}_{2}, \mathrm{P}_{2} \mathrm{O}_{5}, \mathrm{CaCO}_{3}, \mathrm{Na}_{2} \mathrm{CO}_{3}\right.$ and $\left.\mathrm{AgNO}_{3}\right)$ were mixed and homogenized, using a planetary ball milling process for 1 hour at $300 \mathrm{rpm}$. Agate vessel and balls were used. The powder was then calcined for 8 hours at $800^{\circ} \mathrm{C}$. Subsequently, the melt-quenching process was undertaken, using a platinum crucible. The melt temperature was $1350^{\circ} \mathrm{C}$, and the melt time was 1 hour. The glass was melted twice to improve the samples homogeneity. After quenched, all samples were annealed at $400^{\circ} \mathrm{C}$ for 15 hours and then slowly cooled inside the annealing furnace, to minimize the internal mechanical stresses resulting from quenching.

\section{2 | Structural and morphological characterization}

The structure of the samples was investigated through X-ray powder diffraction (XRD), Raman and FTIR spectroscopies. 
The XRD diffractograms were obtained at room temperature, on an Advance $8 \mathrm{X}$-ray powder diffractometer using $\mathrm{CuK}_{\alpha}$ radiation $(\lambda=1.54056 \AA)$ operating at $45 \mathrm{kV}$, and $40 \mathrm{~mA}$, with a curved graphite monochromator, an automatic divergence slit, a progressive receiving slit, and a flat plane sample holder in a Bragg-Brentano parafocusing configuration. A scan step of $0.02^{\circ}$ in $1 \mathrm{~s}$ in the $2 \theta$ angle range of $10-60^{\circ}$ were the measurement parameters.

The Raman spectroscopy of the bulk samples was carried out in a Jobin Yvon spectrometer using an $\mathrm{Ar}^{+}$laser $(\lambda=532 \mathrm{~nm})$, and the spectra were obtained in a back-scattering geometry, between 200 and $1500 \mathrm{~cm}^{-1}$. The FTIR spectra were recorded in the ATR mode, between 400 and $1500 \mathrm{~cm}^{-1}$, on a Nicolet Avatar 360 spectrometer, using pellets composed by $\mathrm{KBr}$ mixed with the powder of each sample, in a weight ratio of 200:1 mg.

For the electrical measurements, the samples were polished until parallel surfaces were achieved, with thicknesses of about $1 \mathrm{~mm}$. The surface area of all samples is close to that of a disk with $10 \mathrm{~mm}$ diameter. The opposite parallel faces of the samples were painted with silver conducting paste. The DC electrical conductivity $\left(\sigma_{\mathrm{DC}}\right)$ of the samples was measured with a Keithley 617 electrometer, capable of measuring currents down to $10^{-14} \mathrm{~A}$. This measurement was performed in the temperature range between 200 and $400 \mathrm{~K}$, using a nitrogen bath cryostat setup. During the electrical measurements, the samples were kept in a helium atmosphere, to avoid moisture, and minimize thermal gradients. The AC electrical conductivity $\left(\sigma_{\mathrm{AC}}\right)$ was also measured in the temperature range of 200-400 K, using the same bath cryostat, with a Network Analyzer, Agilent 4294, operating between $40 \mathrm{~Hz}$ and $110 \mathrm{MHz}$ and in the $\mathrm{Cp}-\mathrm{Rp}$ configuration (Capacitance in parallel with Resistance). In both measurements, DC and AC, the temperature of the samples were controlled by an Oxford IT-C4 and measured using a platinum sensor. In both DC and $\mathrm{AC}$, the activation energy $\left(E_{\mathrm{a}}\right)$ was calculated for the high-temperature range, by fitting the data to the Arrhenius equation (Equation (1)) ${ }^{27-29}$ :

$$
\sigma=\sigma_{0} \exp \left(-\frac{E_{\mathrm{a}}}{K_{\mathrm{B}} T}\right)
$$

where $\sigma_{0}$ is a preexponential factor, $E_{\mathrm{a}}$ the activation energy, $K_{\mathrm{B}}$ the Boltzmann constant, and $T$ the temperature. The $E_{\mathrm{a}}$ can be calculated from the slope of $\ln \left(\sigma_{\mathrm{DC}}\right)$ versus $1 / T$.

The permittivity was calculated using Equation (2). ${ }^{30-33}$

$$
\varepsilon^{*}=\varepsilon^{\prime}-j^{\prime \prime}=C_{\mathrm{p}} \frac{d}{\varepsilon_{0} A}-j \frac{d}{\omega R_{\mathrm{p}} \varepsilon_{0} A}
$$

where $C_{\mathrm{p}}$ and $R_{\mathrm{p}}$ represent the measured capacitance and resistance, $d$ is the sample thickness, $A$ the electrode area and $\varepsilon_{0}$ the permittivity of the empty space $\left(8.8542 \times 10^{-12} \mathrm{~F} / \mathrm{m}\right)$. The AC conductivity, $\sigma_{\mathrm{AC}}$, was calculated using the relation (3) ${ }^{31-34}$ :

$$
\sigma_{\mathrm{AC}}=\varepsilon^{\prime \prime} \omega \varepsilon_{0}
$$

where $\omega$ is the angular frequency, $\varepsilon_{0}$ is the dielectric permittivity of free space $\left(8.854 \times 10^{-12} \mathrm{~F} / \mathrm{m}\right)$ and $\varepsilon^{\prime \prime}$ is the imaginary part of the complex permittivity. To determine the AC activation energy $\left(E_{\mathrm{a}(\mathrm{AC})}\right)$ these results were adjusted using the Arrhenius expression, in the same way that it was made for $E_{\mathrm{a}(\mathrm{DC})}$ (Equation (1)).

From the complex permittivity values the complex modulus can be calculated, which is defined as the inverse of the complex permittivity, being the real and imaginary parts given by the following equations, respectively ${ }^{34}$ :

$$
\begin{aligned}
& M^{\prime}=\frac{\varepsilon^{\prime}}{\varepsilon^{\prime 2}+\varepsilon^{\prime \prime 2}} \\
& M^{\prime \prime}=\frac{\varepsilon^{\prime \prime}}{\varepsilon^{\prime 2}+\varepsilon^{\prime \prime 2}}
\end{aligned}
$$

A semi-quantitative analysis of the chemical elements on the surface of the samples was made using a Bruker EDS system coupled to a Vega 3 microscope from TESCAN. The measurements were made in several surface points with an electron beam spot of $5 \mu \mathrm{m}$ in diameter.

\section{3 | Cytotoxicity tests}

Samples were checked for cytotoxicity using the extract method and Vero cells according to the International Standard ISO 10993-5. Bioglass samples were incubated during 48 hours at $37^{\circ} \mathrm{C}$ in the culture medium for extract production. Two surface to volume of medium ratios were tested: $3 \mathrm{~cm}^{2} / \mathrm{mL}$ and $1.5 \mathrm{~cm}^{2} / \mathrm{mL}$. Negative controls (viable cells) and positive controls (cells in a cytotoxic environment created by the addition of dimethyl sulphoxide to the medium) were established. After 48 hours in contact with the extracts, a colorimetric viability assay using resazurin was performed. ${ }^{35}$

\subsection{Antibacterial activity}

To assess the antimicrobial activity $E$ coli K12 DSM498 and $S$ aureus NCTC8325 were used as reference strains. The bacterial strains were grown overnight at $37^{\circ} \mathrm{C}$ using the $\mathrm{LB}$ Broth ${ }^{36}$ until they reach approximately $10^{9} \mathrm{CFU} / \mathrm{mL}$ and then a series of 10-fold dilutions of each culture were prepared in molten LB solidified with agar $0.8 \% \mathrm{w} / \mathrm{v}$. An inoculum of $100 \mu \mathrm{L}$ of the appropriate dilution was deposited on the surface of the material (one single drop in contact with the surface) and the samples incubated at $37^{\circ} \mathrm{C}$ during 48 hours. The number of colonies (CFU) in each sample was registered under a stereomicroscope at $12.5 \mathrm{X}$ magnification. Each experiment was perf ormed at least 3 times.

\section{3 | RESULTS AND DISCUSSION}

The XRD diffractograms of the glass without silver (BG0) and glass with silver (BG2) are shown in Figure 1. The XRD 


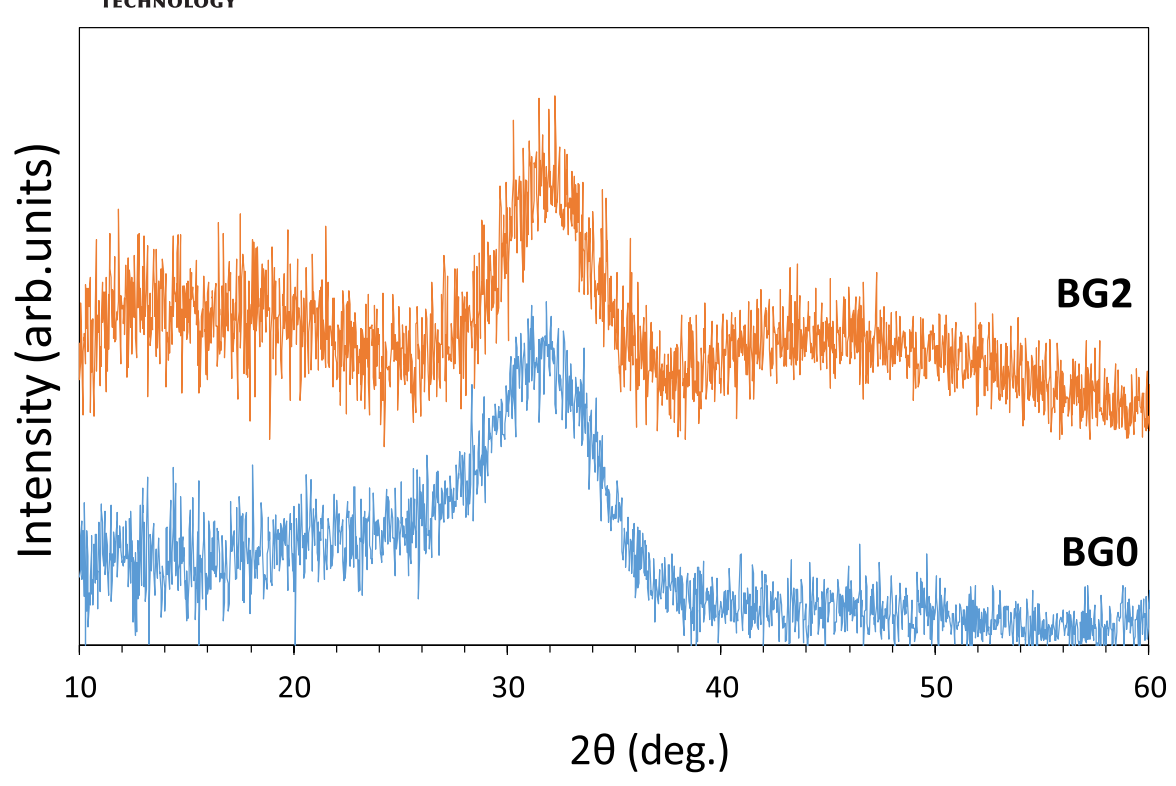

F IG URE 1 XRD patterns of BG0 and BG2 samples

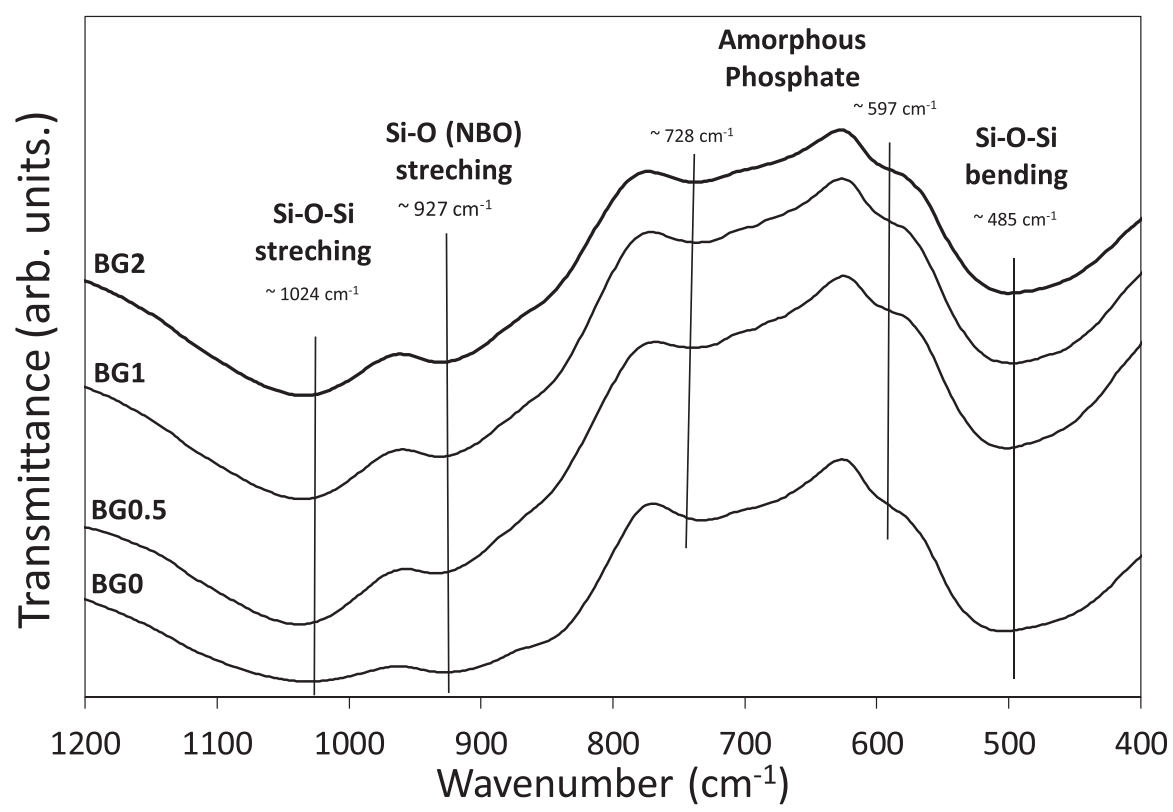

F IGURE 2 FTIR spectra of all the glasses

patterns of both samples are very similar, showing only an amorphous phase and demonstrating that the chosen exchange conditions did not affect the structure of the glass to promote any devitrification. However, the possible existence of crystalline phases should not be excluded. If they exist, they should be small in size and number, which is difficult to detect, due to the low amount of incorporated silver.

Figure 2 shows the FTIR spectra of all samples. The characteristic absorption bands of the amorphous bioglass can be observed at around 1024, 927 and $485 \mathrm{~cm}^{-1}$. These bands are predominantly due to the $\mathrm{Si}-\mathrm{O}$ bonding vibrations. They are well assigned to $\mathrm{Si}-\mathrm{O}-\mathrm{Si}$ and $\mathrm{Si}-\mathrm{O}$ stretching vibration modes and to the $\mathrm{Si}-\mathrm{O}-\mathrm{Si}$ bending mode, respectively. The shoulder at $597 \mathrm{~cm}^{-1}$ is related to amorphous phosphate. ${ }^{37,38}$ Not only the band at $597 \mathrm{~cm}^{-1}$ but also the band at $728 \mathrm{~cm}^{-1}$ is related to P-O-P bonding. ${ }^{39,40}$ In agreement with the results of XRD, the FTIR measurements also do not indicate any type of modification in the glass matrix with the addition of silver.

As with the techniques discussed above, the Raman spectra of the different samples are similar. The broad bands indicate the presence of amorphous phases (Figure 3). A more detailed analysis, performed by deconvoluting the Raman spectroscopy bands (Figure 4), revealed additional information. The best adjustment allows the identification of the vibrations characteristic of the different structural groups present in accordance with published data. ${ }^{41}$ Deconvolution shows the following vibrations in the amorphous sample: 406, 621, $665,863,942,956$, and $1029 \mathrm{~cm}^{-1}$. These bands are assigned to symmetric oxygen stretching of $\mathrm{Si}-\mathrm{O}-\mathrm{Si}$, rocking motions 


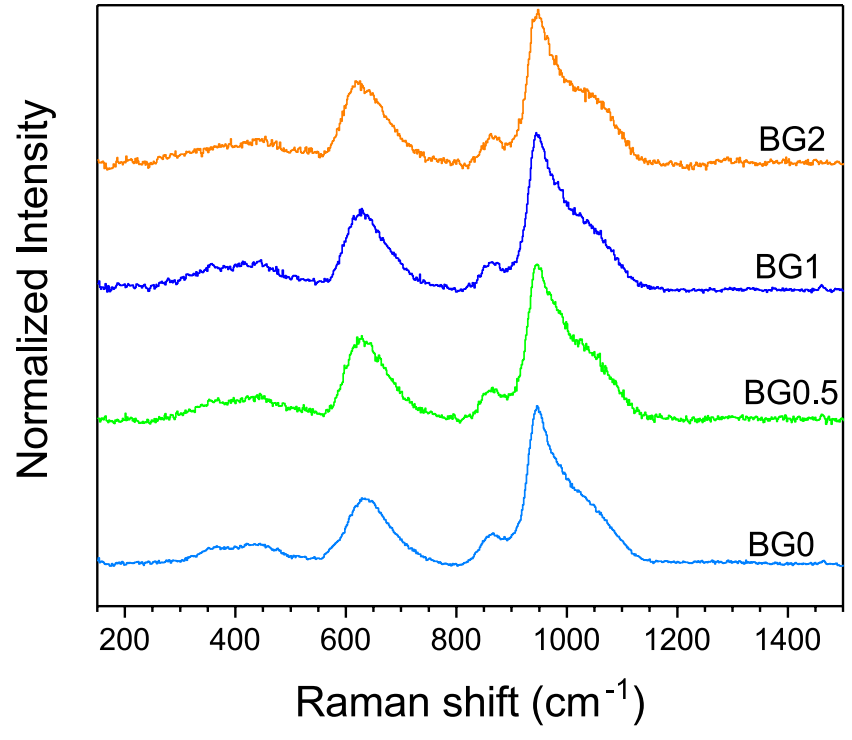

F I G U RE 3 Raman spectra of all glasses

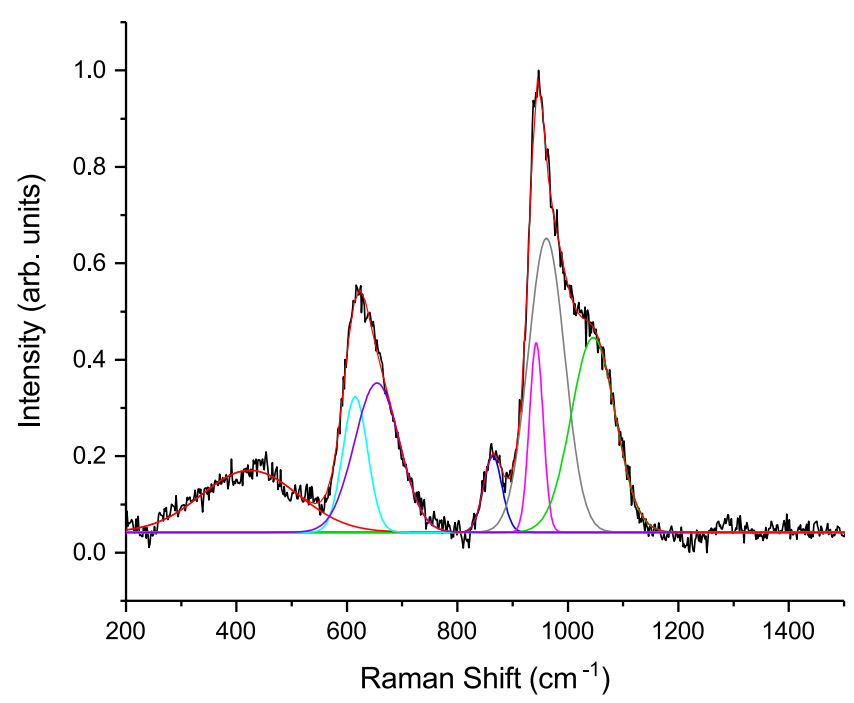

F I G URE 4 Raman spectrum of the BG1 glass, including the deconvolution of all bands

of bridging oxygen in structural units that contains nonbringing oxygen, oxygen bending motion, symmetric stretching of $\mathrm{Q}^{0}\left(\mathrm{SiO}_{4}{ }^{4-}\right)$, symmetric stretching of $\mathrm{Q}^{2}\left(\mathrm{Si}_{2} \mathrm{O}_{6}{ }^{4-}\right)$, P-O-P stretching, asymmetric stretching of bridging oxygen in all Q species, respectively, according to the literature. ${ }^{41}$ Figure 5 shows the sum of the areas of the bands associated with nonbridging oxygen vibrations.

Figure 6 represents the EDS spectra that allow a semiquantitative analysis of the constituent elements of the base bioglass (BG0) and of the bioglass with silver, in this case the sample BG2. The band relative to silver element increases with the increase in its concentration. However, the concentration of silver is low than the expected. This can be

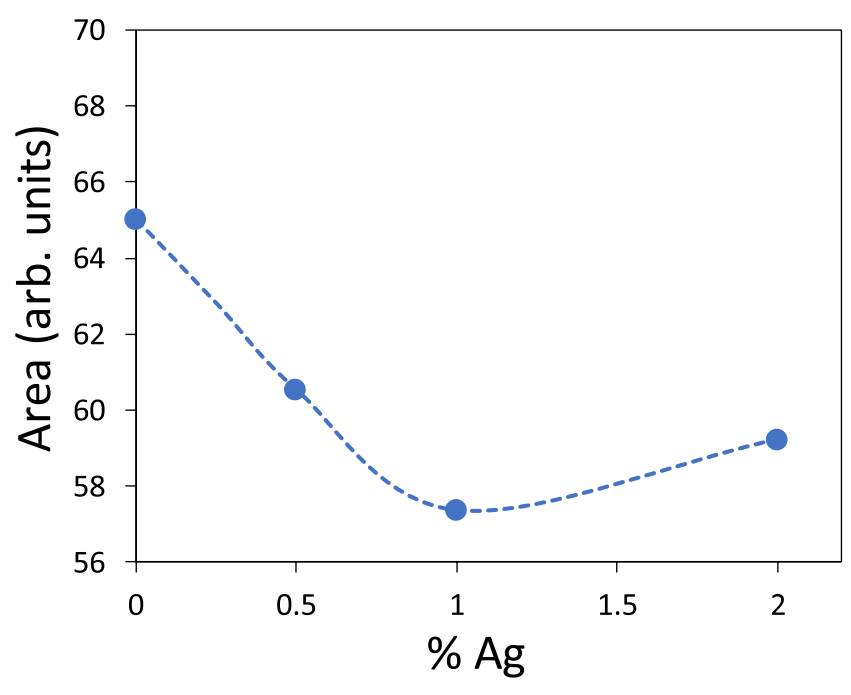

F IG URE 5 The sum of the areas of the bands associated with nonbridging oxygen vibrations

associated with losses in the synthesis method. Other chemical elements, besides those that are part of the network, were not detected.

Figure 7 shows the graph of the DC conductivity, on a logarithmic scale, as a function of the inverse temperature. All samples display a thermally activated behavior because conductivity increases with increasing temperature. Above about $250 \mathrm{~K}$, the behavior is linear and can be adjusted to the Arrhenius model. Applying this model, it was possible to calculate the activation energies of this conduction mechanism in the temperature range shown in the inset. It was found that the energy tends to increase with increasing silver concentration while the conductivity tends to decrease (Table 1). Since the conductivity depends of the number of charge carriers and their mobility, the increase in the activation energy suggests a decrease in the mobility of the charge carriers, which may contribute to the decrease of the conductivity. In addition to this factor, the number of charge carriers also influences the reduction of conductivity due to the possible segregation of silver in the glass network, which will consequently decrease the number of "available" carriers. In addition, and since the number of silver ions inserted into the glass structure is lower than the number of sodium ions that should be replaced, as the EDS results indicate, the total number of charge carriers should decrease with the increase of silver. Thus, if the number of modifiers decreases, the number of nonbridging oxygen (NBO) ions decreases. An indicator of the decrease in the number of NBO is verified by Raman spectroscopy. As mentioned, the sum of the areas of the Raman vibration bands associated with nonbridging oxygen vibrations (Figure 5) shows a tendency to a decrease of the NBO bonds with the increase of Ag content, which is in 

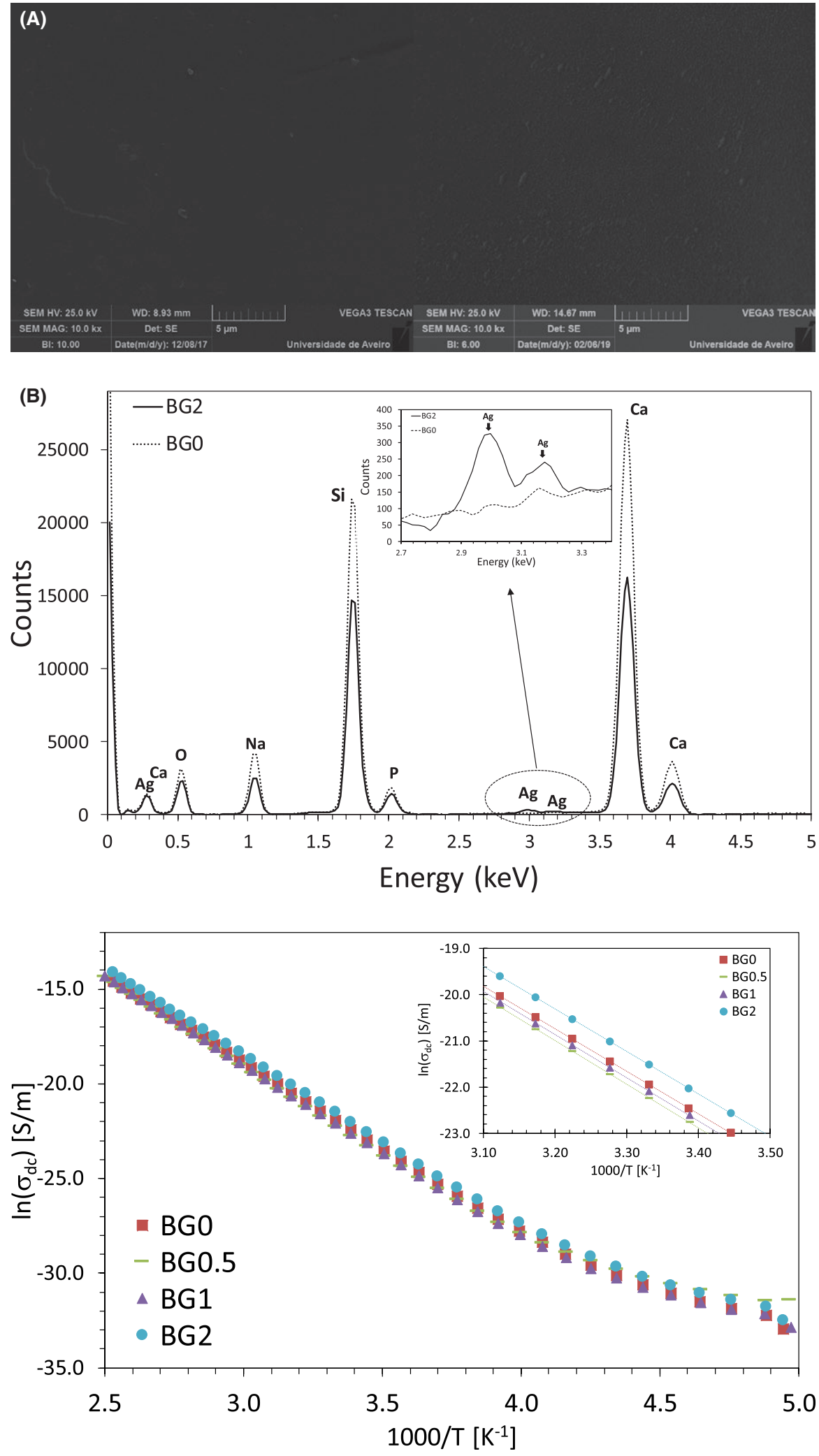

F IG URE 6 A) SEM images of BG0 and BG2. B) EDS data of BG0 and BG2 (inset shows the $\mathrm{Ag}$ bands in detail)
F I G URE 7 Logarithm of the DC conductivity versus $1000 / \mathrm{T}$, at $10 \mathrm{kHz}$, for all samples (Inset is a magnification of the high temperature measuring region; lines represent the Arrhenius fit) agreement with the DC conductivity results (Table 1). This observation suggest that the number of $\mathrm{Ag}$ ions that can be included into the glass structure as free ions, acting as network modifiers, is smaller than that the number of Na ions that were replaced with the Ag ions. This can be due to the possible segregation and/or loss of silver ions during the preparation process and should be function of the quantity of Ag content.

Table 2 shows that AC conductivity decreases with the increase of silver content. Verifying that the activation 
TA B L E 1 DC conductivity $\left(\sigma_{\mathrm{DC}}\right)$ and DC activation energy at $360 \mathrm{~K}$ and $10 \mathrm{kHz}$

\begin{tabular}{lll} 
Samples & $\begin{array}{l}\boldsymbol{\sigma}_{\mathbf{D C}}\left(\times \mathbf{1 0}^{-\mathbf{8}}\right) \\
{[\mathbf{S} / \mathbf{m}]}\end{array}$ & $\begin{array}{l}\boldsymbol{E}_{\mathbf{a}(\mathbf{D C})} \\
{[\mathbf{k J} / \mathbf{m o l}]}\end{array}$ \\
\hline BG0 & 4.77 & 76.35 \\
BG0.5 & 4.03 & 79.59 \\
\hline BG1 & 4.44 & 78.47 \\
BG2 & 1.84 & 80.50 \\
\hline
\end{tabular}

TA B L E 2 AC conductivity $\left(\sigma_{\mathrm{AC}}\right)$, AC activation energy $\left(E_{\mathrm{a}(\mathrm{AC})}\right)$, dielectric constant $\left(\varepsilon^{\prime}\right)$, and dielectric loss $(\tan \delta)$, of all samples at $300 \mathrm{~K}$ and $10 \mathrm{kHz}$

\begin{tabular}{lllll} 
Samples & $\begin{array}{l}\boldsymbol{\sigma}_{\mathrm{AC}} \\
{\left[\mathbf{1 0}^{-\mathbf{7}} \mathbf{S} / \mathbf{m}\right]}\end{array}$ & $\begin{array}{l}\boldsymbol{E}_{\mathrm{a}(\mathbf{A C})} \\
{[\mathbf{k J} / \mathbf{m o l}]}\end{array}$ & \multicolumn{1}{c}{$\boldsymbol{\varepsilon}^{\prime}$} & $\tan \boldsymbol{\delta}$ \\
\hline BG0 & 1.92 & 37.95 & 13.60 & 0.018 \\
BG0.5 & 0.82 & 35.67 & 11.00 & 0.013 \\
BG1 & 0.77 & 35.88 & 9.85 & 0.014 \\
BG2 & 0.62 & 35.77 & 10.93 & 0.010 \\
\hline
\end{tabular}

energy does not change significantly, it can be concluded that the decrease in AC conductivity is due to the reduction in the number of charge carriers. In these samples, with the exception of the base sample, the presence of a dielectric relaxation was detected, and the frequency peak is shifted to higher frequencies with the rise of temperature (Figure 8). This variation can be adjusted using the Arrhenius model and in this way calculate the activation energy of this relaxation process (Table 3 ). The activation energy values of this relaxation phenomenon are much higher than those obtained for the AC conductivity, which suggests that the entities responsible for both phenomena are not the same. Must be mention that in the dielectric analysis
TAB LE 3 Activation energy $\left(E_{\mathrm{a}}\right)$ of dielectric relaxation of all the samples

\begin{tabular}{ll} 
Samples & $\begin{array}{l}\boldsymbol{E}_{\mathbf{a}} \\
{[\mathbf{k J} / \mathbf{m o l}]}\end{array}$ \\
\hline BG0 & - \\
\hline BG0.5 & 81.91 \\
\hline BG1 & 77.04 \\
\hline BG2 & 77.79 \\
\hline
\end{tabular}

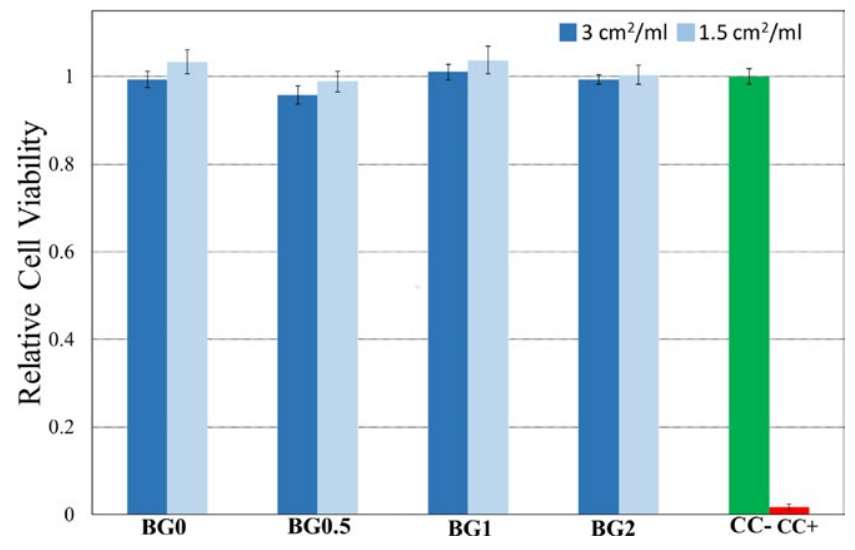

F I G URE 9 Cytotoxicity of the extracts prepared with the different glasses toward Vero cells. A relative cell viability above $90 \%$ indicates the absence of cytotoxic effects towards the cells used

we used the modulus formalism, $\left(\mathrm{M}^{*}=1 / \varepsilon^{*}\right)$, because it minimizes the electro-sample interface capacitance contribution at low frequencies and emphasize small capacitances features. ${ }^{42}$ This dielectric relaxation behavior was not observed in other formalism, such as the permittivity or impedance. Thus, the relaxation behavior should be related with electrical dipoles form due to the presence of silver in the glass network as a network modifier ion.
F I G URE 8 Imaginary part of the modulus versus frequency, at several temperatures, for BG1 sample. The inset shows the Arrhenius fit

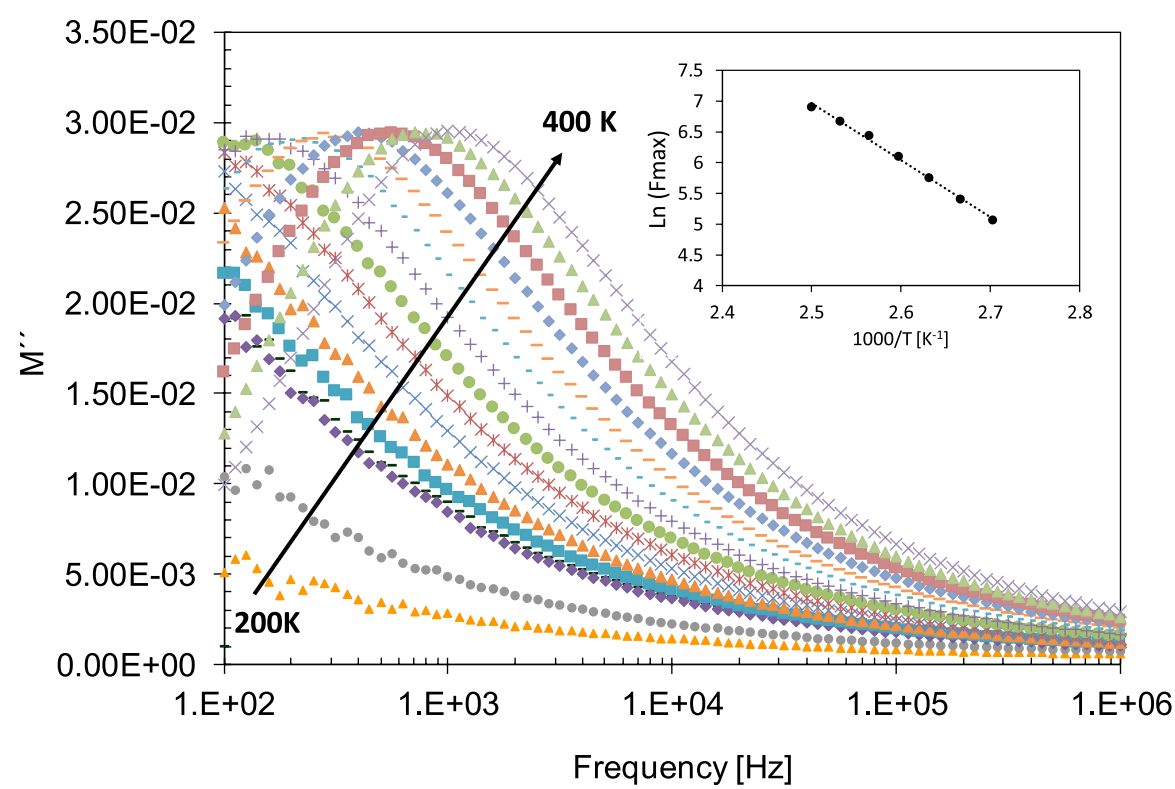


TA B L E 4 The effect of the bioglass and silver-containing bioglass on Staphylococcus aureus and Escherichia coli

\begin{tabular}{lll} 
Samples & S aureus $(\mathrm{CFU} / \mathrm{mL})$ & $\boldsymbol{E}$ coli $(\mathrm{CFU} / \mathrm{mL})$ \\
BG0 & $1.85 \times 10^{9} \pm 2.8 \times 10^{8}$ & $1.6 \times 10^{9} \pm 1.8 \times 10^{9}$ \\
BG0.5 & 0 & 0 \\
BG1 & 0 & 0 \\
BG2 & 0 & 0 \\
\hline
\end{tabular}

Results of the cytotoxicity test show that none of the samples with the different concentrations of silver present a toxic behavior towards Vero cells when compared to the positive $(\mathrm{CC}+)$ and negative $(\mathrm{CC}-$ ) controls (Figure 9). The absence of cytotoxicity of $45 \mathrm{~S} 5$ bioglasses modified by the addition of up to $2 \%$ silver suggests that they can be used in biologic applications without causing harmful effects.

The antimicrobial activity test summarized in Table 4 indicates that the inclusion of Ag promotes antibacterial activity. The results show that $\mathrm{Ag}$ has a more severe inhibitory effect towards
E coli when compared to $S$ aureus. This observation is consonant with the results of other studies ${ }^{24,43}$ and most probably due to the different nature of the bacteria cell-wall. In the sample with the lowest silver concentration tested (BG0.5), a decrease in cell viability of $E$ coli is observed when compared to the control, that is, the sample without silver (BG0). The same behavior is observed with the $S$ aureus species (Table 4). However, at higher silver concentration, samples BG0.5, BG1, and BG2, total inhibition of growth is shown for both microorganisms (Figure 10).

\section{CONCLUSIONS}

Amorphous bioglasses, with the 45S5 base composition, containing silver were synthesized using the melt-quenching method. It was observed that concentrations of silver above $2 \%$ were not feasible, due to clear segregation phenomena. The EDS results reveal that the real content of silver, in all samples, is lower than the expected probably due

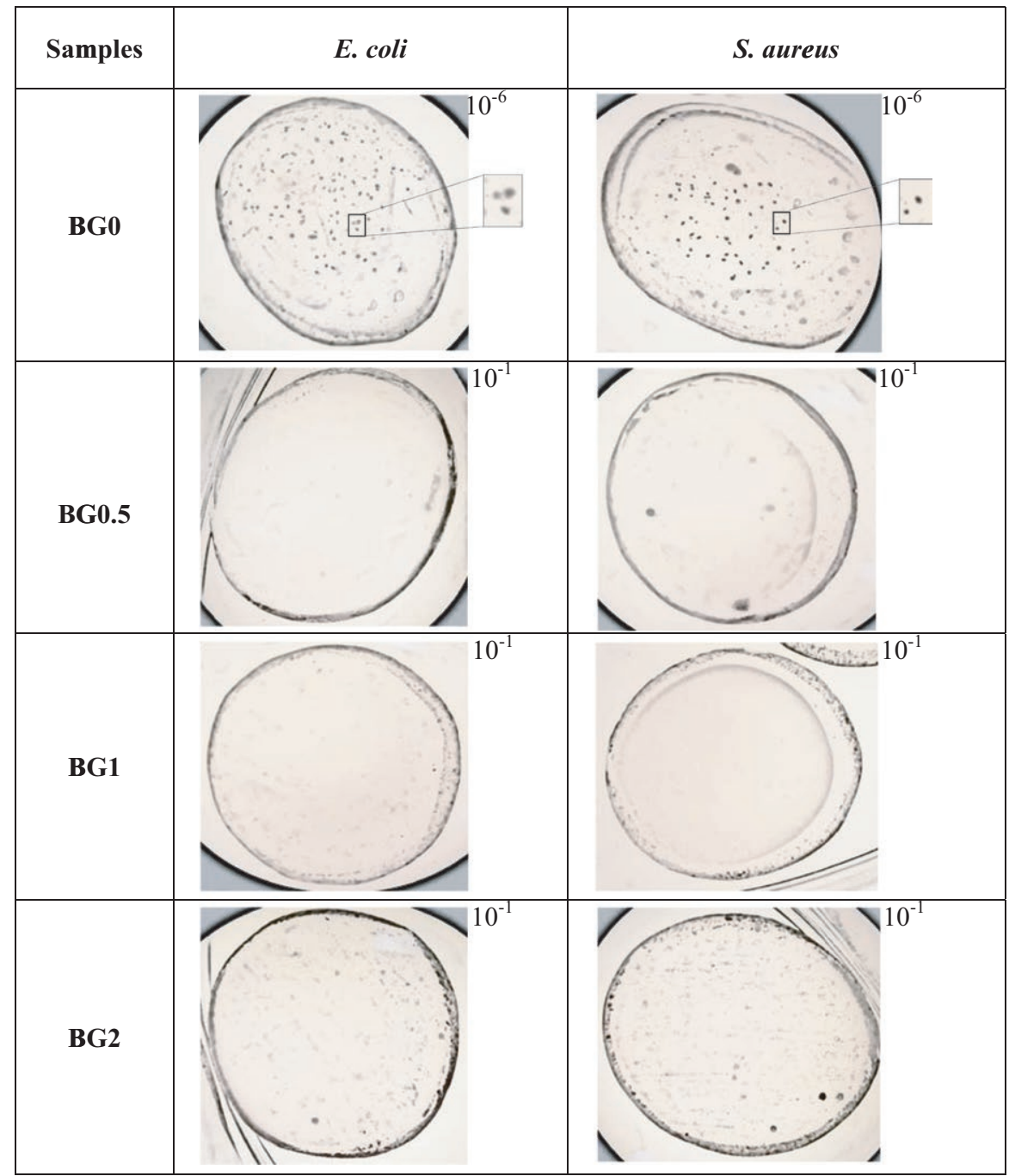

F I G U RE 10 Antibacterial activity of bioglass and silver-containing bioglass against Staphylococcus aureus and Escherichia coli. Top panels inset shows a magnification of bacterial colonies 
to segregation (nonuniform distribution of silver in the glass network) and/or losses during the melting-quenching steps. Raman spectroscopy shows a decrease in the NBO vibration bands with the increase of silver content, which is in agreement with the DC conductivity results and associated with the decrease in charge carriers numbers due to the occurrence of silver segregation. A thermally stimulated dielectric relaxation phenomenon was detected in all samples containing silver ions. Cytotoxicity studies show that all samples are viable for biomedical applications. The antimicrobial evaluation indicates that samples with a silver concentration in the range from $0.5 \%$ up to $2 \%$ completely prevented the growth of both $S$ aureus and E coli at the highest bacterial cell density tested.

This work shows that the prepared bioglasses can be used as coating material for dental implants with antimicrobial activity or in the production of scaffolds for bone tissue engineering.

\section{ACKNOWLEDGMENTS}

The authors are grateful by the FEDER funds through the COMPETE 2020 Program and National Funds through FCT-Portuguese Foundation for Science and Technology under the project UID/CTM/50025/2013, UCIBIO, REQUIMTE UID/Multi/04378/2013, and DENTALBLAST project (ref. $\left.n^{\circ} 17956\right)$.

\section{ORCID}

Sílvia R. Gavinho (D) https://orcid.org/0000-0001-6216-3735

\section{REFERENCES}

1. Charalampakis G, Leonhardt A, Rabe P, Dahlen G. Clinical and microbiological characteristics of peri-implantitis cases: a retrospective multicentre study. Clin Oral Impl Res. 2012;23:1045-54.

2. Talreja PS, Gayathri GV, Mehta DS. Treatment of an early failing implant by guided bone regeneration using resorbable collagen membrane and bioactive glass. J Indian Soc Periodontol. 2013;17:131-6.

3. Zitzmann NU, Berglundh T. Definition and prevalence of peri-implant diseases. J Clin Periodontol. 2008;35:286-91.

4. Balamurugan A, Balossier G, Laurent-Maquin D, Pina S, Rebelo A, Faure J, et al. An in vitro biological and anti-bacterial study on a sol-gel derived silver-incorporated bioglass system. Dent Mater J. 2008;24:1343-51.

5. Lee N, Robinson J, Lu H. Biomimetic strategies for engineering composite tissues. Curr Opin Biotechnol. 2016;4:064-74.

6. Jones JR. Review of bioactive glass: from hench to hybrids. Acta Biomater. 2013;9:4457-86.

7. Lu HH, Thomopoulos S. Functional attachment of soft tissues to bone: development, healing, and tissue engineering. Annu Rev Biomed Eng. 2013;15:201-26.

8. Mercier C, Follet-Houttemane C, Pardini A, Revel B. Influence of $\mathrm{P}_{2} \mathrm{O}_{5}$ content on the structure of $\mathrm{SiO}_{2}-\mathrm{Na}_{2} \mathrm{O}-\mathrm{CaO}-\mathrm{P}_{2} \mathrm{O}_{5}$ bioglasses by ${ }^{29}$ Si and ${ }^{31}$ P MAS-NMR. Revel J Non-Cryst Solids. 2011;357:3901-9.
9. Hench LL. Bioceramics: from concept to clinic. J Am Ceram Soc. 1991;74:1487-510.

10. Lizzi F, Villat C, Attik N, Jackson P, Grosgogeat B, Goutaudier C. Mechanical characteristic and biological behavior of implanted and restorative bioglasses used in medicine and dentistry: a systematic review. Dent Mater J. 2017;33:702-12.

11. Vichery C, Nedelec JM. Bioactive glass nanoparticles: from synthesis to materials design for biomedical applications. Materials. 2016;9:1-17.

12. Lefebvre L, Chevalier J, Gremillard L, Zenati R, Thollet G, Bernache-Assolant D, et al. Structural transformations of bioactive glass 45S5 with thermal treatments. Acta Mater. 2007;55:3305-13.

13. Hench LL. The story of bioglass ${ }^{\circledR}$. J Mater Sci: Mater Med. 2006;17:967-78.

14. Mariappan CR, Ranga N. Influence of silver on the structure, dielectric and antibacterial effect of silver doped bioglass-ceramic nanoparticles. Ceram Int. 2017;43:2196-201.

15. Bellucci D, Bolelli G, Cannillo V, Cattini A, Sola A. In situ Raman spectroscopy investigation of bioactive glass reactivity: simulated body fluid solution vs TRIS-buffered solution. Mater Charact. 2011;62:1021-8.

16. Tian T, Wu C, Chang J. Preparation and in vitro osteogenic, angiogenic and antibacterial properties of cuprorivaite $(\mathrm{CaCuSi} 4 \mathrm{O} 10$, Cup) bioceramics. RSC Adv. 2016;6:45840-9.

17. Kumar A, Vemula PK, Ajayan P, John G. Silver-nanoparticle-embedded antimicrobial paints based on vegetable oil. Nat. Mater. 2008;7:236-41.

18. Sirelkhatim A, Mahmud S, Seeni A, Kaus N, Ann LC, Bakhori S, et al. Review on zinc oxide nanoparticles: antibacterial activity and toxicity mechanism. Nano-Micro Lett. 2015;7:219-42.

19. Leung YH, Ng A, Xu X, Shen Z, Gethings LA, Wong MT, et al. Mechanisms of antibacterial activity of $\mathrm{MgO}$ : non-ROS mediated toxicity of $\mathrm{MgO}$ nanoparticles towards Escherichia coli. Small. 2014;10:1171-83.

20. Russell AD, Hugo WB. Antimicrobial activity and action of silver. In: Ellis GP, Luscombe DK, editors. Progress in medicinal chemistry. Vol. 31. chapter 7. Amesterdam: Elsevier Science B.V.; 1994:351-70

21. Rosa RM, Silva JC, Sanches IS, Henriques C. Simultaneous photoinduced cross-linking and silver nanoparticle formation in a PVP electrospun wound dressing. Mater Lett. 2017;207:145-8.

22. Valappil SP, Pickup DM, Carroll DL, Hope CK, Pratten J, Newport RJ, et al. Effect of silver content on the structure and antibacterial activity of silver-doped phosphate-based glasses. Antimicrob. Agents Chemother. 2007;51:4453-61.

23. Jung WK, Koo HC, Kim KW, Shin S, Kim SH, Park YH. Antibacterial activity and mechanism of action of the silver ion in Staphylococcus aureus and Escherichia coli. Appl Environ Microbiol. 2008;74:2171-8.

24. Ouay B, Stellacci F. Antibacterial activity of silver nanoparticles: a surface science insight. Nano Today. 2015;10:339-54.

25. Bellantone M, Coleman NJ, Hench LL. Bacteriostatic action of a novel four-component bioactive glass. J Biomed Mater Res. 2000;51:484-90.

26. Nandi SK, Mahato A, Kundu B, Mukherjee P. Doped bioactive glass materials in bone regeneration. In: Zorzi AR, editor. Adv. Tech. in bone regen. Rijeka, Croatia: InTech; 2016:275-328.

27. Macdonald JR. Impedance spectroscopy: emphasizing solid materials and analysis. New York, NY: John Wiley \& Sons; 1987. 
28. Graça M, Silva M, Valente MA. Preparation, structure, morphology, dc and ac conductivity of the 88SiO2-6Li2O-6Nb2O5 (\% mole) sol-gel derived glass-ceramics. J. Sol-Gel Sci. Technol. 2007;42:1-8.

29. Graça M, Silva MG, Sombra A, Valente MA. Electrical and dielectrical properties of $\mathrm{SiO} 2-\mathrm{Li} 2 \mathrm{O}-\mathrm{Nb} 2 \mathrm{O} 5$ glass and glass-ceramics obtained by thermoelectric treatments. J Non-Cryst Solids. 2006;352:5199-204.

30. El-Mallawany R. Tellurite glasses handbook: physical properties and data. Florida: CRC Press; 2002.

31. Graça M, Silva M, Sombra AS, Valente MA. Electrical characterization of $\mathrm{SiO}_{2} \mathrm{LiNbO}_{3}$ glass and glass ceramics using dc conductivity, TSDC measurements and dielectric spectroscopy. J Non-Cryst Solids. 2007;353:4390-4.

32. Belattar J, Graça M, Costa LC, Achour ME, Brosseau C. Electric modulus-based analysis of the dielectric relaxation in carbon black loaded polymer composites. J Appl Phys. 2010;107:124111-6.

33. Graça M, Silva M, Valente MA. Structural and electrical characteristics of $\mathrm{LiNbO} 3$ embedded in a $34 \% \mathrm{SiO} 2$ glass matrix. J Eur Ceram Soc. 2008;28:1197-203.

34. Macedo PB, Moynihan CT, Bose R. The long time aspects of this correlation function, which are obtainable by bridge techniques at temperatures approaching the glass transition. Phys Chem Glasses. 1972;13:171-6.

35. Vieira T, Silva JC, Borges JP, Henriques C. Synthesis, electrospinning and in vitro test of a new biodegradable gelatin-based poly(ester urethane urea) for soft tissue engineering. Eur Polym J. 2018;103:271-81.

36. Miller JH. Experiments in molecular genetics. Cold Spring Harbor, NY: Cold Spring Harbor Laboratory; 1972.
37. Boccaccini AR, Chen Q, Lefebvre L, Gremillard L, Chevalier J. Sintering, crystallization and biodegradation behavior of Bioglassderived glass-ceramics. Faraday Discuss. 2007;136:27-44.

38. Chatzistavrou X, Zorba T, Kontonasaki E, Chrissafis K, Koidis P, Paraskevopoulos KM. Following bioactive glass behavior beyond melting temperature by thermal and optical methods. Phys Stat Sol (a). 2004;201:944-51.

39. Exarhos GJ, Miller PJ, Risen WM. Interionic vibrations and glass transitions in ionic oxide metaphosphate glasses. J Chem Phys. 1974;60:4145-55.

40. Aqdim S, Ouchetto M. Elaboration and structural investigation of iron (III) phosphate glasses. Adv Mater Phys Chem. 2013;3:332-9.

41. Dziadek M, Zagrajczuk B, Jelen P, Olejniczak Z, CholewaKowalska K. Structural variations of bioactive glasses obtained by different synthesis routes. Ceram Int. 2016;42:14700-9.

42. Silva CC, Valente MA, Graca M, Sombra A. The modulus formalism used in the dielectric analysis of hydroxyapatite and calcium phosphate with titanium formed by dry ball milling. J Non-Cryst Solids. 2005;351:2945-50.

43. Feng QL, Wu J, Chen GQ, Cui FZ, KimTN K. A mechanistic study of the antibacterial effect of silver ions on Escherichia coli and Staphylococcus aureus. J Biomed Mater Res. 2000;52:662-8.

How to cite this article: Gavinho SR, Prezas PR, Ramos DJ, et al. Nontoxic glasses: Preparation, structural, electrical and biological properties. Int $J$ Appl Ceram Technol. 2019;00:1-10. https://doi. org/10.1111/ijac.13243 